\title{
Early learning experiences, school entry skills and later mathematics achievement in South Africa
}

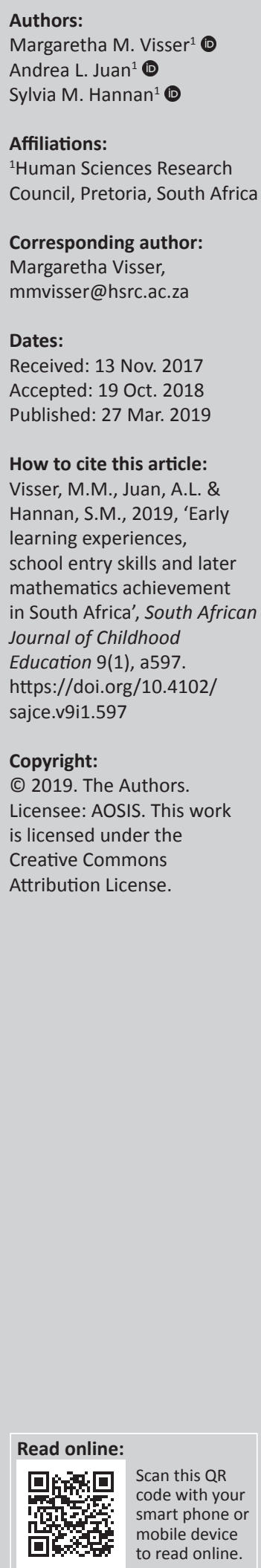

Background: The acquired skill set prior to school entry has emerged as an important issue in research and policy internationally. Much evidence exists advocating the importance of early numeracy and literacy skills in later academic achievement and economic outcomes of students.

Aim: The goal of this study was to determine the association between parents' reports of engagement in pre-Grade 1 learning activities and school entry skills, and mathematics achievement in Grade 5.

Setting: This study was based on empirical evidence using South African data from the 2015 Trends in International Mathematics and Science Study.

Methods: These relationships were investigated by using stepwise multiple regression analysis.

Results: It was found that parent reports of engagement in pre-Grade 1 activities and acquired school entry skills are positively associated with student achievement at the Grade 5 level. This held even when taking other contextual home factors into account: socio-economic status and the frequency of speaking the language of the test at home.

Conclusion: The role of the home is important in preparing children for school and has an impact on their later achievement. The home context should therefore be a key consideration in enhancing the South African education system. Parent reports are a good indicator of engagement in early learning activities and acquired numeracy and literacy skills prior to school entry.

Keywords: school entry skills; early learning; numeracy; literacy; home environment; TIMSS.

\section{Introduction}

Early childhood is an opportune period during which pertinent development has the prospect of cultivating potential within individuals. The fleetingness of this critical period, however, means that there is a distinct risk of leaving that potential untapped, never to be fully developed. This becomes evident in academic achievement later in life.

In the quest to improve the low educational performance of students in South Africa it is important to understand the early learning experiences of children, the skills with which children enter the school system and how these factors are associated with later achievement of students.

In South Africa, the majority of children come from low socio-economic backgrounds. In 2015 approximately 13 million children in South Africa lived in poverty (Statistics South Africa 2017). Typically, children from these homes are seldom exposed to books or regular literacy practices such as storybook reading (Pretorius 2014:55). Thus, children from different socio-economic backgrounds are entering the schooling system with different levels of literacy and numeracy skills.

The South African government has attempted to address this through the National Integrated Early Childhood Development Policy, which aims to transform early childhood development service delivery in South Africa, covering the period from conception until the year before children enter formal school (Republic of South Africa [RSA] 2015). Early learning requires parents and caregivers to play a role, as well as early learning programmes in centres that complement the parents' role.

The data from the 2015 Trends in International Mathematics and Science Study (TIMSS) for South African Grade 5 students provide the opportunity to explore these relationships by using parent 
reports of early educational activities and acquired skills. In so doing, this article aims to advance research in this area within the South African context. This article addressed the following research questions:

- How are parents' reports of pre-Grade 1 early learning activities and acquired literacy and numeracy skills associated with mathematics performance of Grade 5 students in South Africa?

- How does the predictor value of parents' reports of preGrade 1 early learning activities and acquired literacy and numeracy skills change when variables for socio-economic status and frequency of speaking the language of the test at home are controlled for in a regression model?

We use a conceptual lens, adapted from studies that highlight the importance of children's home experiences in literacy and numeracy development, to guide this article (Black et al. 2016; Bradley 2002; Institute of Medicine 2000; Melhuish et al. 2008a). In so doing, we ultimately examine the role of early learning in students' school achievement.

\section{Literature review}

Within the first few years of a child's life, the foundation is laid for cognitive functioning, behavioural, social, emotional and self-regulatory capacities, as well as physical health (Institute of Medicine 2000; Richter et al. 2012). Studies have found that between birth and the age of 5 years, children rapidly develop foundational capabilities. Development within this period proceeds at a pace greater than that of any subsequent life stages, and subsequent development builds on these initial capabilities (Institute of Medicine 2000; Kotze 2015).

\section{Early learning}

Various studies have highlighted the importance of good quality preschools for children, as this has an important impact on children's cognitive and socio-emotional outcomes (Brinkman et al. 2016; Ramey \& Ramey 2004). As learning is not restricted only to formal schooling, research also began to focus more on the importance of the home environment. The home environment plays an essential role in the early development of children, as the home environment has an impact on what children learn and can do, what they expect and believe, and how they approach others during the early years. This subsequently starts them off along differing pathways as they move into the school-age years. Parents and other regular caregivers form an integral part of the early childhood period. Within supportive and nurturing relationships with parents and caregivers, children are able to grow and thrive (Institute of Medicine 2000:389).

Activities conducted within the home environment, such as reading to children, storytelling, singing, playing with household objects, using complex language, responsiveness and warmth in interactions expose young children to experiences that promote early development and are associated with positive developmental outcomes (Black et al. 2016; Bradley 2002; Melhuish et al. 2008a). Stimulating activities may enhance development by helping children with specific skills. A study by Siegler and Ramani (2009) showed that a variety of aspects of preschool children's early numerical understanding and skills development, including number identification, number line estimation, counting, size comparison and learning answers to mathematics problems, are improved by playing a linear number board game as described in their study. They found that an hour of playing this game per day led to a significant improvement in the development of low socio-economic preschool children's mathematics skills (Siegler \& Ramani 2009). Chin and Zakaria (2015) designed a games-based learning module for preschool students and found that the use of it significantly improved the results of students' number concepts and number operations. Understanding of these basic mathematics concepts is crucial to further mathematics learning (Chin \& Zakaria 2015).

School entry abilities can be linked to preschool abilities (Melhuish et al. 2008b:109), which are in turn linked to abilities cultivated before a child enters preschool. Growing evidence highlights the role of parenting for children's skills development and ongoing achievement (Melhuish et al. 2008a, 2008b).

\section{Parental attributes and early learning}

Parent and caregiver attributes are also important in early learning. Parental education levels are associated with parental teaching styles, the home literacy environment and investments in a range of resources that contribute to the promotion of learning. These are dimensions of human capital that are related to early learning and educational attainment when children enter formal schooling (Institute of Medicine 2000:282). In some cases, parents are unable to invest extensively in developing critical skills in their children at an early age because of a lack of resources. In addition, parents may be unaware of the importance of investing in their child's early skill formation (Schady, Galiani \& Souza 2006:2). Several studies have found that the more positive home learning environments of high-income versus lowincome children account for as much as half of the gap in test scores of preschool children and as much as one-third of the gap in the achievement scores of school-age children (Smith, Brooks-Gunn \& Klebanov 1997). In general, poorer families provide less stimulating environments, while more affluent parents are able to use more developmentally enhancing activities (Melhuish et al. 2008a:4). Children exposed to persistent or transient poverty have been found to have greater cognitive and behavioural deficits at age 5 than children in non-poor families (Duncan, Brooks-Gunn \& Klebanov 1994:307). Some deficits can be attributed to health problems associated with poverty, but the greatest part can be explained by reduced emotional support and less cognitive stimulation from their parents (Melhuish et al. 2008a:110).

\section{Developing skills through early learning}

Cunha et al. (2006:703) explain that 'skill begets skill' and that skill formation is a life cycle process that continues throughout a person's life. Skill attainment at one stage of the life cycle 
consequently raises skill attainment later on. Early childhood education is therefore an integral part of basic education, as the skills formed during this period are necessary for the attainment of future skills (Cunha et al. 2006; Heckman, Stixrud \& Urzua 2006). Motivation fosters skill and skill fosters motivation in a dynamic process, and it is therefore crucial for children to be motivated to learn and engage early on in life (Cunha et al. 2006:697).

Academic achievement in adolescence and beyond has been associated with academic skills present at the time of entering school (Melhuish et al. 2008b:109). Those children who enter school 'ready to learn' have a higher chance of doing well in school, staying in school and achieving learning (UNICEF 2012:17). Academic achievement is a cumulative process involving improving existing skills, as well as mastering new skills (Pungello, Kupersmidt \& Burchinal 1996). Duncan et al. (2007:4) suggest that if achievement later on occurs as the result of a sequential process of acquiring skills, then the strengthening of children's skills before they enter school may facilitate their mastery of more advanced skills at an earlier age. Furthermore, it may lead to an increase in their ultimate level of achievement (Duncan et al. 2007:4). Families play a vital role in the process of skill formation, which Cunha et al. (2006) highlight as being more important than the role of schools. Studies have found that children's early performance on literacy tasks in preschool and their early mathematical abilities predict academic performance throughout the first 3 years of formal schooling and beyond (Duncan et al. 2007; Institute of Medicine 2000).

Duncan et al. (2007) investigated six longitudinal studies, examining the association among various aspects of children's readiness for school and their later achievement in reading and mathematics. The results showed that across the six studies examined, the strongest predictors of later achievement were school entry mathematics, reading and children's attention skills. The analysis controlled for family background and individual factors, such as cognitive, attention and socio-emotional skills prior to school entry. The results therefore highlighted the association between these factors and achievement above and beyond other influencing factors.

\section{Other influences on achievement: Socio-economic status and home language}

Before children enter preschool, striking disparities in both cognitive and non-cognitive skills are evident. These differences are strongly associated with social and economic circumstances, and they are predictive of subsequent academic performance (Institute of Medicine 2000; Schady et al. 2006; Siegler 2009).

More than anywhere else in the world, the South African apartheid government used language policy as a tool of social control. Thus, the issue of language cannot be overlooked in the South African context, where only 31\% of Grade 5 students who participated in the TIMSS 2015 almost always spoke the language of instruction at home (Reddy et al. 2016). These students tended to perform better when the language of learning and teaching was the same as the language that they spoke at home (Juan \& Visser 2017).

Despite the importance of the language of instruction, there is no consensus among educationalists, researchers and policymakers and limited empirical evidence about best practices regarding language of instruction for South African primary school students. Some argue for the use of English as soon as possible to ensure fluency before entering Grade 1; however, linguistic theories promote a solid foundation in the child's home language before learning a second language (Taylor \& Coetzee 2013). Taylor and Coetzee (2013) conducted an empirical study using data of 9000 primary schools serving children from the poorest households in South Africa and found that as language policies are currently being implemented, the choice to use mother-tongue instruction as opposed to English instruction in Grades 1, 2 and 3 generally leads to better English learning in the long run.

\section{Research methods and design}

\section{Data source and sample}

The data used for this article are from the TIMSS 2015, which was conducted by the International Association for the Evaluation of Educational Achievement (IEA). Forty-eight countries participated in the TIMSS at the Grade 4 or 5 levels, including South Africa. From the population of 15783 South African schools that offered Grade 5 classes in 2013, the IEA selected a stratified random sample of 300 schools, of which 297 schools participated in the TIMSS 2015. The sample was stratified by province, type of school (public or independent) and language of instruction (Afrikaans, English or dual medium). A random selection process of intact classes (as opposed to the selection of individual students) was applied for each sampled school. A sample of 10932 Grade 5 students from South Africa participated in the TIMSS 2015. In addition 10376 parents or caregivers of the participating students completed an early learning survey. The data were weighted to the population of South African Grade 5 students.

\section{Measures}

This section describes how the variables that were included in stepwise multiple regression analyses were prepared. Firstly, variables were created for categories of engagement in early learning activities at home pre-Grade 1. Secondly, two variables were created as proxies for the acquired levels of preschool numeracy and literacy skills of the student. These were based on parents' or caregivers' reports of their child's ability to perform certain numeracy and literacy tasks before entering Grade 1. Thirdly, a description of the calculation of a proxy variable for socio-economic status of students was provided. Fourthly, a variable on how often the student spoke the language of the test at home and finally, a description of how the mathematics achievement score was derived were presented. 


\section{Measurement of variables related to engaging in pre-Grade 1 activities at home}

The set of data collection instruments for the TIMSS 2015 included an early learning survey, which was completed by the parents or caregivers of the participating Grade 5 students. Parents were asked the frequency with which their child was involved in 17 different activities at home prior to entering Grade 1. These activities were as follows: read books; tell stories; sing songs; play with alphabet toys; talk about things they had done; play word games; write letters or words; read aloud signs and labels; say counting rhymes or sing counting songs; play with number toys; count different things; play games involving shapes; play with building blocks or construction toys; play board or card games; write numbers; and watch educational television (TV) programmes.

Parents were required to choose from three options in relation to the frequency with which they, or someone else in the home, did the activity with their child: never or almost never; sometimes; and often. The 17 variables were subjected to principal component analysis and three variables were generated containing the factor scores of the extracted components (see Tables 1 and 2). The three variables were related to three themes: (1) reading and writing of letters and numbers; (2) playing educational games and playing with toys; and (3) singing songs and telling and reading stories. The extracted variables explained $49 \%$ of the variance in the sample (see Table 1).

The internal consistency and reliability of the extracted components were measured as follows (see Table 2): the reading and writing subscale consisted of seven items $(\alpha=0.79)$; the playing games subscale consisted of six items $(\alpha=0.80)$; and the songs and stories subscale consisted of four items $(\alpha=0.61)$. The first two subscales' internal consistency and reliability measures were in line with the generally accepted value of 0.8 (Field 2009). Many resources advise treading with caution when a Cronbach's alpha measure of below 0.7 is calculated, but according to Field (2009:675) a value of 0.61 is acceptable based on a smaller number of items (in this instance four items), the sample size and the context of the research. The internal consistency and reliability of the songs and stories subscale was considered acceptable based on the number of items and also because the items described an underlying concept within the social sciences context of early learning activities.

\section{Measurement of variables for the level of numeracy and literacy skills of students before entering Grade 1, based on parents' or caregivers' reports}

Parents responded to two other sets of questions related to their child's capabilities in literacy and numeracy before they entered Grade 1. Parents were required to rate the ability of

TABLE 2: Components extracted through principal component analysis.

\begin{tabular}{lccc}
\hline Pre-Grade 1 activities & \multicolumn{3}{c}{ Component } \\
\cline { 2 - 4 } & $\mathbf{1}$ & $\mathbf{2}$ & $\mathbf{3}$ \\
\hline Write letters or words & 0.717 & 0.212 & 0.109 \\
Write numbers & 0.708 & 0.208 & 0.047 \\
\hline Read books & 0.645 & 0.205 & 0.178 \\
\hline Talk about what you had read & 0.636 & 0.143 & 0.280 \\
\hline Read aloud signs and labels & 0.569 & 0.296 & 0.235 \\
\hline Watch educational TV programmes & 0.483 & 0.147 & 0.085 \\
\hline Count different things & 0.460 & 0.325 & 0.275 \\
\hline Play with building blocks or construction toys & 0.083 & 0.744 & 0.180 \\
\hline Play with number toys (e.g. blocks with numbers) & 0.226 & 0.741 & 0.150 \\
\hline Play with alphabet toys (e.g. blocks with letters & 0.236 & 0.713 & 0.083 \\
of the alphabet) & & & \\
\hline Play games involving shapes (e.g. shape sorting & 0.266 & 0.711 & 0.125 \\
toys, puzzles) & & & \\
\hline Play word games & 0.378 & 0.532 & 0.118 \\
\hline Play board or card games & 0.289 & 0.434 & 0.227 \\
\hline Sing songs & 0.077 & 0.103 & 0.780 \\
\hline Tell stories & 0.201 & 0.152 & 0.674 \\
\hline Say counting rhymes or sing counting songs & 0.241 & 0.410 & 0.478 \\
\hline Talk about things you had done & 0.374 & 0.165 & 0.432 \\
\hline
\end{tabular}

Note: Rotated component matrix: rotation converged in five iterations; extraction method: principal component analysis; rotation method: varimax with Kaiser normalisation.

TABLE 1: Results of the principal component analysis on engagement in pre-Grade 1 activities, reported by the student's parents or caregivers.

\begin{tabular}{|c|c|c|c|c|c|c|c|c|c|}
\hline \multirow[t]{2}{*}{ Component } & \multirow[t]{2}{*}{ Total } & \multicolumn{3}{|c|}{ Initial eigenvalues } & \multicolumn{3}{|c|}{ Extraction sums of squared loadings } & \multicolumn{2}{|c|}{ Rotation sums of squared loadings } \\
\hline & & Variance $(\%)$ & Cumulative (\%) & Total & Variance $(\%)$ & Cumulative (\%) & Total & Variance (\%) & Cumulative (\%) \\
\hline 1 & 6.095 & 35.855 & 35.855 & 6.095 & 35.855 & 35.855 & 3.260 & 19.179 & 19.179 \\
\hline 2 & 1.212 & 7.127 & 42.982 & 1.212 & 7.127 & 42.982 & 3.183 & 18.723 & 37.902 \\
\hline 3 & 1.019 & 5.993 & 48.976 & 1.019 & 5.993 & 48.976 & 1.883 & 11.074 & 48.976 \\
\hline 4 & 0.893 & 5.253 & 54.229 & - & - & - & - & - & - \\
\hline 5 & 0.842 & 4.952 & 59.181 & - & - & - & - & - & - \\
\hline 6 & 0.798 & 4.691 & 63.873 & - & - & - & - & - & - \\
\hline 7 & 0.747 & 4.395 & 68.268 & - & - & - & - & - & - \\
\hline 8 & 0.688 & 4.048 & 72.316 & - & - & - & - & - & - \\
\hline 9 & 0.640 & 3.762 & 76.078 & - & - & - & - & - & - \\
\hline 10 & 0.616 & 3.623 & 79.700 & - & - & - & - & - & - \\
\hline 11 & 0.566 & 3.329 & 83.029 & - & - & - & - & - & - \\
\hline 12 & 0.542 & 3.189 & 86.218 & - & - & - & - & - & - \\
\hline 13 & 0.520 & 3.060 & 89.278 & - & - & - & - & - & - \\
\hline 14 & 0.502 & 2.950 & 92.228 & - & - & - & - & - & - \\
\hline 15 & 0.470 & 2.764 & 94.992 & - & - & - & - & - & - \\
\hline 16 & 0.440 & 2.590 & 97.581 & - & - & - & - & - & - \\
\hline 17 & 0.411 & 2.419 & 100.000 & - & - & - & - & - & - \\
\hline
\end{tabular}

Note: Extraction method: principal component analysis. 
their child in relation to six literacy tasks, on a four-point Likert rating scale: not at all with a value of 0 , not very well valued as 1, moderately well as 2 and very well as 3 . The literacy tasks included: recognise most of the letters of the alphabet; read some words; read sentences; read a story; write letters of the alphabet; and write some words. Internal consistency and reliability of these six items were established $(\alpha=0.88)$. A new variable, created by calculating the sum of the values of these six variables for each student, was used as a proxy for the students' acquired level of literacy skills before entering Grade 1.

Parents' reports of numeracy skills, by responding to three questions, were again recorded on a four-point Likert rating scale: not at all, up to 10, up to 20 and up to 100 or higher. Parents had to rate the child's ability to perform the following tasks: count by himself or herself; recognise written numbers; and write numbers. Internal consistency and reliability of the three items were established $(\alpha=0.88)$. A new variable, created in the same manner as for literacy skills, was used as a proxy for the students' acquired level of numeracy skills before entering Grade 1.

\section{Measurement of a proxy for socio-economic status of students}

Grade 5 students were required to complete a student questionnaire as part of the TIMSS. One of the questions elicited information about the availability of 15 selected assets in students' homes. The assets included the following: a computer or tablet (iPad) of your own; a computer or tablet (iPad) that is shared with other people at home; study desk or table for your use; your own room; Internet connection; your own cell phone; a gaming system (e.g. PlayStation ${ }^{\circledR}, \mathrm{Wii}^{\circledR}, \mathrm{XBox}^{\circledR}$ ); dictionary; electricity; running tap water; television; water flush toilets; motor car; landline telephone; and fridge. A variable containing the sum of the responses was created as a proxy for socioeconomic status of students. Thus, the maximum value of this variable was 15 (see Table 3).

\section{Measurement of the frequency of speaking the test language at home}

Students were asked how often they had spoken the language of testing at home, ranging from never to always. The students' responses were recoded as follows: never as 0 ; sometimes as 1; almost always as 2; and always as 3. A variable relating to the frequency of speaking the language of the test at home was included in the regression analysis.

\section{Measurement of mathematics achievement}

Mathematics achievement scores were calculated on a scale with a centre point of 500 and a standard deviation of 100 . The achievement tests broadly represented the curricula of the 48 participating countries. The process to ensure nonbiased testing included adapting items according to data from curriculum analysis and the piloting of instruments. The achievement tests were administered in each school's language of instruction, either English or Afrikaans.

To obtain estimates of students' proficiency in mathematics that are both accurate and cost-effective, the IEA applied matrix-sampling assessment designs that grouped the entire pool of items into a series of blocks. Each student completed four blocks, each containing approximately 10-14 assessment items. As far as possible, within each block the distribution of items across content and cognitive domains matched the distribution across the item pool overall. Individual students were thus tested on a subset of the complete pool of assessment items. Five plausible scores were calculated for each student based on the performance of all students on all tested items. All quantitative analysis of mathematics achievement reports on the average of the five plausible scores.

Table 3 presents descriptive statistics on the variables described and Table 4 presents a correlation matrix that shows the strength of the correlation between variables.

All of the independent variables were significantly and positively correlated with the dependent variable: mathematics achievement. Reading and writing, $r(7405)=$ $0.13, p<0.001$; playing games, $r(7405)=0.19, p<0.001$; and songs and stories, $r(7405)=0.16, p<0.001$, were weakly correlated with mathematics achievement. Literacy skills, $r(10211)=0.27, p<0.001$; numeracy skills, $r(10064)=0.27$, $p<0.001$; language, $r(10779)=0.26, p<0.001$; and socioeconomic status, $r(10884)=0.36, p<0.001$, were moderately correlated with mathematics achievement.

TABLE 3: Descriptive statistics of the prepared variables.

\begin{tabular}{|c|c|c|c|c|c|c|c|c|c|c|}
\hline \multirow[t]{2}{*}{ Prepared variables } & \multirow[t]{2}{*}{$n$ sample } & \multirow[t]{2}{*}{ Minimum } & \multirow[t]{2}{*}{ Maximum } & \multicolumn{2}{|c|}{ Mean } & \multirow[t]{2}{*}{ SD } & \multicolumn{2}{|c|}{ Skewness } & \multicolumn{2}{|c|}{ Kurtosis } \\
\hline & & & & Statistic & SE & & Statistic & SE & Statistic & SE \\
\hline 1. Reading and writing & 7407 & -3.624 & 2.982 & 0.05 & 0.011 & 0.973 & -0.446 & 0.028 & 0.032 & 0.057 \\
\hline 2. Playing games & 7407 & -2.791 & 2.971 & 0.03 & 0.012 & 0.993 & -0.192 & 0.028 & -0.580 & 0.057 \\
\hline 3. Songs and stories & 7407 & -3.595 & 2.837 & 0.01 & 0.012 & 1.003 & -0.336 & 0.028 & -0.255 & 0.057 \\
\hline 4. Literacy skills & 10213 & 0 & 18 & 11.06 & 0.048 & 4.852 & -0.385 & 0.024 & -0.797 & 0.048 \\
\hline 5. Numeracy skills & 10066 & 0 & 9 & 4.81 & 0.026 & 2.616 & 0.069 & 0.024 & -0.944 & 0.049 \\
\hline 6. Language & 10781 & 0 & 3 & 1.39 & 0.009 & 0.946 & 0.607 & 0.024 & -0.672 & 0.047 \\
\hline 7. Home assets & 10886 & 0 & 15 & 8.22 & 0.032 & 3.342 & -0.273 & 0.023 & -0.376 & 0.047 \\
\hline 8. Mathematics achievement & 10932 & 93 & 764 & 379.45 & 0.931 & 97.381 & 0.362 & 0.023 & -0.043 & 0.047 \\
\hline Valid $n$ (listwise) & 7186 & - & - & - & - & - & - & - & - & - \\
\hline
\end{tabular}

Note: Statistics presented in this table are from unweighted data.

$\mathrm{SE}$, standard error; SD, standard deviation. 


\section{Data analysis}

The data were subjected to exploratory and inferential data analysis. Stepwise multiple regression analysis was performed. This analysis was deemed most appropriate as the procedure only enters predictors that contribute to predicting mathematics performance by starting with the variable that contributes the most. The first regression analysis examined the predictor value of engagement in preGrade 1 activities and school entry skills in terms of numeracy and literacy skills on mathematics performance. A second regression analysis investigated the association between pre-Grade 1 activities, parental reports of school entry skills, socio-economic status of the student and frequency of speaking the test language at home on mathematics performance. In conducting two regressions, we were able to firstly investigate the quantitative effect of parents' reports of students' engagement in pre-Grade 1 early learning activities and acquired literacy and numeracy skills before entering Grade 1 on their mathematics performance in Grade 5. Secondly, we were able to investigate how these effects

TABLE 4: Pearson correlation matrix of the prepared variables.

\begin{tabular}{lcccccccc}
\hline $\begin{array}{l}\text { Prepared } \\
\text { variables }\end{array}$ & $\mathbf{1}$ & $\mathbf{2}$ & $\mathbf{3}$ & $\mathbf{4}$ & $\mathbf{5}$ & $\mathbf{6}$ & $\mathbf{7}$ & $\mathbf{8}$ \\
\hline 1 & 1.000 & - & - & - & - & - & - & - \\
2 & -0.022 & 1.000 & - & - & - & - & - & - \\
3 & 0.003 & 0.001 & 1.000 & - & - & - & - & - \\
4 & $0.339 *$ & $0.185^{*}$ & $0.088^{*}$ & 1.000 & - & - & - & - \\
5 & $0.170 *$ & $0.099 *$ & $0.049 *$ & $0.435^{*}$ & 1.000 & - & - & - \\
6 & $0.054 *$ & $0.119 *$ & $0.174 *$ & $0.082 *$ & $0.096 *$ & 1.000 & - & - \\
7 & $0.049 *$ & $0.190 *$ & $0.106 *$ & $0.108 *$ & $0.131 *$ & $0.219 *$ & 1.000 & - \\
8 & $0.128 *$ & $0.189 *$ & $0.158 *$ & $0.269 *$ & $0.266 *$ & $0.258 *$ & $0.363 *$ & 1.000 \\
\hline
\end{tabular}

Note: Statistics presented in this table are from unweighted data.

*, Correlation is significant at the 0.01 level (two-tailed). changed when controlling for home socio-economic status and frequency of speaking the test language at home.

\section{Ethical considerations}

The data used in the study were from the Trends in International Mathematics and Science Study (TIMSS). Ethical clearance for conducting the TIMSS in South Africa was awarded by the Research Ethics Clearance Committee of the Human Sciences Research Council on 14 July 2014 (ethical clearance number: REC 1/19/03/14).

\section{Results and findings}

\section{Home activities, acquired literacy and numeracy skills and mathematics achievement}

A stepwise multiple regression analysis was conducted to evaluate whether involvement in pre-Grade 1 activities and acquired numeracy and literacy skills could predict mathematics performance (see Table 5). At Step 1 of the analysis, numeracy skills entered into the regression equation and were significantly related to mathematics performance $(F[1,7275]=496.20, p<0.001)$. The multiple correlation coefficient was 0.25 , indicating approximately $6.4 \%$ of the variance of mathematics performance could be accounted for by numeracy skills (adjusted $R^{2}=0.064, p<0.001$ ). As recorded in Table 5, all variables were entered into the equation at Step 5 of the analysis and were significantly related to mathematics performance $(F[5,7271]=222.83$, $p<0.001)$. The multiple correlation coefficient was 0.37 , indicating approximately $13.3 \%$ of the variance of mathematics performance could be accounted for by the five independent variables (adjusted $R^{2}=0.132, p<0.001$ ).

TABLE 5: Results of a stepwise regression analysis showing the association between early learning activities at home, pre-Grade 1 literacy and numeracy skills, and mathematics performance.

\begin{tabular}{|c|c|c|c|c|c|c|c|c|}
\hline \multirow{2}{*}{\multicolumn{2}{|c|}{ Model }} & \multicolumn{2}{|c|}{ Unstandardised coefficients } & \multirow{2}{*}{$\begin{array}{c}\text { Standardised coefficients } \\
\text { Beta }\end{array}$} & \multirow[t]{2}{*}{$t$} & \multirow[t]{2}{*}{ Sig. } & \multicolumn{2}{|c|}{$95.0 \%$ confidence interval for B } \\
\hline & & $\beta$ & SE & & & & Lower bound & Upper bound \\
\hline \multirow[t]{2}{*}{1} & (Constant) & 336.491 & 0.300 & - & 1120.868 & $0.000^{*}$ & 335.902 & 337.079 \\
\hline & Numeracy skills & 9.746 & 0.052 & 0.237 & 185.748 & $0.000^{*}$ & 9.643 & 9.849 \\
\hline \multirow[t]{3}{*}{2} & (Constant) & 340.369 & 0.296 & - & 1151.610 & $0.000 *$ & 339.790 & 340.948 \\
\hline & Numeracy skills & 9.002 & 0.052 & 0.219 & 174.138 & $0.000 *$ & 8.901 & 9.104 \\
\hline & Playing games & 19.374 & 0.128 & 0.190 & 151.585 & $0.000 *$ & 19.124 & 19.625 \\
\hline \multirow[t]{4}{*}{3} & (Constant) & 342.700 & 0.293 & - & 1170.670 & $0.000 *$ & 342.126 & 343.273 \\
\hline & Numeracy skills & 8.535 & 0.051 & 0.207 & 166.563 & $0.000^{*}$ & 8.434 & 8.635 \\
\hline & Playing games & 19.470 & 0.126 & 0.191 & 154.152 & $0.000 *$ & 19.223 & 19.718 \\
\hline & Songs and stories & 14.906 & 0.126 & 0.146 & 118.227 & $0.000^{*}$ & 14.659 & 15.153 \\
\hline \multirow[t]{4}{*}{4} & (Constant) & 315.816 & 0.397 & - & 795.495 & $0.000 *$ & 315.037 & 316.594 \\
\hline & Numeracy skills & 6.708 & 0.054 & 0.163 & 124.118 & $0.000 *$ & 6.602 & 6.814 \\
\hline & Playing games & 17.154 & 0.127 & 0.168 & 134.639 & $0.000 *$ & 16.904 & 17.403 \\
\hline & Songs and stories & 14.123 & 0.125 & 0.139 & 112.731 & $0.000 *$ & 13.877 & 14.368 \\
\hline \multirow[t]{6}{*}{5} & (Constant) & 322.007 & 0.417 & - & 772.189 & $0.000 *$ & 321.190 & 322.824 \\
\hline & Numeracy skills & 6.596 & 0.054 & 0.160 & 122.166 & $0.000 *$ & 6.490 & 6.701 \\
\hline & Playing games & 17.591 & 0.127 & 0.173 & 137.984 & $0.000 *$ & 17.341 & 17.841 \\
\hline & Songs and stories & 14.311 & 0.125 & 0.141 & 114.401 & $0.000 *$ & 14.066 & 14.556 \\
\hline & Literacy skills & 2.629 & 0.033 & 0.112 & 80.030 & $0.000 *$ & 2.565 & 2.693 \\
\hline & Reading and writing & 6.289 & 0.132 & 0.062 & 47.638 & $0.000^{*}$ & 6.030 & 6.547 \\
\hline
\end{tabular}

Note: Coefficients, dependent variable - mathematics score.

$t, \mathrm{t}$ statistic (The $\mathrm{t}$ statistic is the coefficient divided by its standard error); $\beta$, unstandardised population regression coefficient; Sig., significance; SE, standard error.

$*, p \leq 0.001$. 
Thus, the regression equation for predicting mathematics performance was as follows: mathematics performance = $322.007+(6.596 *$ numeracy skills $)+(17.591 *$ playing games $)+(14.311 *$ songs and stories $)+(2.629 *$ literacy skills $)+(6.289 *$ reading and writing $)$.

Playing games and with toys at home prior to entering school had the highest association with mathematics performance of Grade 5 students $(\beta=0.17, p<0.001)$. Not surprisingly, numeracy skills acquired before entering Grade 1 had the second highest association with mathematics performance ( $\beta=0.16, p<0.001)$. Exposure to reading and writing activities at home had the lowest association with Grade 5 mathematics performance $(\beta=0.06, p<0.001)$.

\section{The home learning environment}

The second stepwise regression analysis was conducted to see how the predictor value of the independent variables in the first regression model changed when variables for socio-economic status and frequency of speaking the language of the test at home were included in the regression analysis. Thus, the regression model measured the level of association between engagement in pre-Grade 1 activities, numeracy and literacy skills, frequency of speaking the language of the test at home and socio-economic status variables on mathematics performance of Grade 5 students (see Table 6).

At Step 1 of the analysis the independent variable, home assets, was entered into the regression equation and was significantly related to mathematics performance $(F[1,7184]=$ $1311.60, p<0.001)$. The multiple correlation coefficient was 0.39 , indicating approximately $15.4 \%$ of the variance of mathematics performance could be accounted for by home assets (adjusted $R^{2}=0.154, p<0.001$ ). Table 6 shows that all variables were entered into the equation at Step 7 of the analysis and were significantly related to mathematics performance $(F[7,7178]=368.71, p<0.001)$. The multiple

TABLE 6: Results of a stepwise regression analysis showing the association between early learning activities at home, pre-Grade 1 literacy and numeracy skills, socio-economic status, frequency of speaking the test language and mathematics performance.

\begin{tabular}{|c|c|c|c|c|c|c|c|c|}
\hline \multicolumn{2}{|c|}{ Model } & \multicolumn{2}{|c|}{ Unstandardised coefficients } & \multirow{2}{*}{$\begin{array}{c}\text { Standardised coefficients } \\
\text { Beta }\end{array}$} & \multirow[t]{2}{*}{$\boldsymbol{t}$} & \multirow[t]{2}{*}{ Sig. } & \multicolumn{2}{|c|}{$95.0 \%$ confidence interval for B } \\
\hline & & $\beta$ & SE & & & & Lower bound & Upper bound \\
\hline \multirow[t]{2}{*}{1} & (Constant) & 283.06 & 0.323 & & 876.528 & $0.000 *$ & 282.428 & 283.694 \\
\hline & Home assets & 12.61 & 0.036 & 0.421 & 351.544 & $0.000 *$ & 12.542 & 12.683 \\
\hline \multirow[t]{3}{*}{2} & (Constant) & 230.88 & 0.431 & & 535.254 & $0.000 *$ & 230.031 & 231.722 \\
\hline & Home assets & 12.11 & 0.035 & 0.404 & 345.477 & $0.000 *$ & 12.042 & 12.179 \\
\hline & Literacy skills & 4.83 & 0.027 & 0.207 & 176.767 & $0.000 *$ & 4.774 & 4.881 \\
\hline \multirow[t]{4}{*}{3} & (Constant) & 218.03 & 0.428 & & 509.822 & $0.000 *$ & 217.187 & 218.864 \\
\hline & Home assets & 10.35 & 0.036 & 0.345 & 289.397 & $0.000 *$ & 10.276 & 10.416 \\
\hline & Literacy skills & 4.58 & 0.027 & 0.196 & 171.765 & $0.000 *$ & 4.531 & 4.636 \\
\hline & Language & 21.52 & 0.127 & 0.202 & 169.790 & $0.000 *$ & 21.269 & 21.766 \\
\hline \multirow[t]{5}{*}{4} & (Constant) & 207.11 & 0.437 & & 473.427 & $0.000 *$ & 206.250 & 207.965 \\
\hline & Home assets & 10.02 & 0.036 & 0.334 & 281.683 & $0.000 *$ & 9.953 & 10.092 \\
\hline & Literacy skills & 3.59 & 0.028 & 0.154 & 127.345 & $0.000 *$ & 3.537 & 3.648 \\
\hline & Language & 20.94 & 0.126 & 0.197 & 166.538 & $0.000 *$ & 20.695 & 21.188 \\
\hline & Numeracy skills & 5.04 & 0.050 & 0.123 & 101.001 & $0.000 *$ & 4.941 & 5.137 \\
\hline \multirow[t]{6}{*}{5} & (Constant) & 215.30 & 0.453 & & 475.466 & $0.000 *$ & 214.416 & 216.191 \\
\hline & Home assets & 9.65 & 0.036 & 0.322 & 268.840 & $0.000 *$ & 9.578 & 9.718 \\
\hline & Literacy skills & 3.26 & 0.029 & 0.140 & 114.166 & $0.000 *$ & 3.203 & 3.315 \\
\hline & Language & 20.16 & 0.126 & 0.190 & 160.213 & $0.000 *$ & 19.911 & 20.404 \\
\hline & Numeracy skills & 5.03 & 0.050 & 0.122 & 101.183 & $0.000 *$ & 4.931 & 5.126 \\
\hline & Playing games & 7.93 & 0.119 & 0.078 & 66.598 & $0.000 *$ & 7.699 & 8.166 \\
\hline \multirow[t]{7}{*}{6} & (Constant) & 219.83 & 0.459 & & 478.654 & $0.000 *$ & 218.926 & 220.727 \\
\hline & Home assets & 9.47 & 0.036 & 0.316 & 263.560 & $0.000 *$ & 9.402 & 9.543 \\
\hline & Literacy skills & 3.15 & 0.029 & 0.135 & 110.519 & $0.000 *$ & 3.098 & 3.210 \\
\hline & Language & 19.09 & 0.127 & 0.180 & 150.325 & $0.000 *$ & 18.844 & 19.342 \\
\hline & Numeracy skills & 4.96 & 0.050 & 0.121 & 99.910 & $0.000 *$ & 4.857 & 5.052 \\
\hline & Playing games & 8.29 & 0.119 & 0.082 & 69.642 & $0.000 *$ & 8.053 & 8.520 \\
\hline & Songs and stories & 6.36 & 0.117 & 0.063 & 54.381 & $0.000 *$ & 6.127 & 6.586 \\
\hline \multirow[t]{8}{*}{7} & (Constant) & 224.55 & 0.478 & & 470.226 & $0.000 *$ & 223.609 & 225.481 \\
\hline & Home assets & 9.46 & 0.036 & 0.316 & 263.444 & $0.000 *$ & 9.388 & 9.529 \\
\hline & Literacy skills & 2.83 & 0.030 & 0.121 & 94.237 & $0.000 *$ & 2.766 & 2.883 \\
\hline & Language & 18.79 & 0.127 & 0.177 & 147.790 & $0.000 *$ & 18.543 & 19.041 \\
\hline & Numeracy skills & 4.89 & 0.050 & 0.119 & 98.681 & $0.000 *$ & 4.794 & 4.989 \\
\hline & Playing games & 8.63 & 0.119 & 0.085 & 72.368 & $0.000 *$ & 8.396 & 8.863 \\
\hline & Songs and stories & 6.55 & 0.117 & 0.064 & 56.026 & $0.000 *$ & 6.319 & 6.778 \\
\hline & Reading and writing & 4.30 & 0.121 & 0.042 & 35.591 & $0.000 *$ & 4.064 & 4.537 \\
\hline
\end{tabular}

Note: Coefficients, dependent variable - mathematics score.

$t, \mathrm{t}$ statistic (The $\mathrm{t}$ statistic is the coefficient divided by its standard error.); $\beta$, unstandardised population regression coefficient; Sig., significance; $\mathrm{SE}$, standard error.

$*, p \leq 0.001$ 
correlation coefficient was 0.51 , indicating approximately $26.4 \%$ of the variance of mathematics performance could be accounted for by the seven independent variables (adjusted $\left.R^{2}=0.264, p<0.001\right)$. Thus, the regression equation for predicting mathematics performance was: mathematics performance $=224.55+(9.46 *$ home assets $)+(2.83 *$ literacy skills $)+(18.79 *$ language $)+(4.89 *$ numeracy skills $)+(8.63 *$ playing games $)+(6.55 *$ songs and stories $)+(4.30 *$ reading and writing).

The results furthermore showed that the proxy variable for socio-economic status of the student (home assets) had the strongest association with mathematics performance ( $\beta=0.32, p<0.001)$, and the frequency of speaking the language of the test at home had the second highest association $(\beta=0.18, p<0.001)$. Literacy $(\beta=0.121, p<0.001)$ and numeracy skills $(\beta=0.119, p<0.001)$ of students before entering school had the third and fourth highest association with mathematics performance.

\section{Discussion}

The findings show that parents' reports of students' engagement in pre-Grade 1 early learning activities and acquired literacy and numeracy skills are significantly and positively associated with the mathematics performance of Grade 5 students. This is in line with findings from studies conducted in other countries such as those by Black et al. (2016), Bradley (2002) and Melhuish et al. (2008a). Interestingly, reports of engagement in pre-Grade 1 activities related to playing games and playing with toys revealed the strongest positive association with mathematics performance in Grade 5 (see Table 5). This presents an opportunity for programmes or interventions that make parents aware of the importance of play in children's early development, as some studies (Schady et al. 2006) show that parents may not be aware of this fact. This finding furthermore corresponds with findings from studies conducted by Siegler and Ramani (2009) and Chin and Zakaria (2015), which found a relationship between the development of children's mathematics skills and engaging in board games. Based on these findings, suitable games could be recommended and implemented at preschools in South Africa and even introduced through educational television or radio programme broadcasts to reach preschool children at their homes to improve their mathematical skills.

It is important to note that early learning activities at home and acquired numeracy and literacy skills prior to Grade 1 still had a statistically significant association with mathematics performance at the Grade 5 level, even after controlling for socio-economic status and the frequency of speaking the test language at home - this points to the importance of the home. Socio-economic status showed the strongest association with Grade 5 student mathematics performance (see Table 6). This finding is in line with studies that have found that the home learning environments of high-income versus low-income children account for as much as half of the gap in test scores of preschool children and as much as one-third of the gap in the achievement scores of school-age children (Smith et al. 1997). The frequency of speaking the language of testing at home had the second strongest association with mathematics performance (see Table 6). Although there is no consensus regarding language of instruction for South African primary school students, linguistic theories do promote a solid foundation in the child's home language before learning a second language (Taylor \& Coetzee 2013). These point to the conclusion of the importance of what goes on in the home that is associated with students' achievement, in combination with socio-economic status.

The following limitations to this study are acknowledged. The first relates to the use of self-reported data. Self-reported data have been criticised as providing unreliable information in some instances because of inherent social-desirability bias (Gonyea 2005). In addition, the data collected are based on parental recollections of activities that occurred in their home at least 5 years prior to the study. Between the time at which the reported activities took place (prior to Grade 1) and Grade 5, other variables may have had an impact. This includes attendance of early childhood education facilities and Grade R. It is therefore difficult to establish causality between variables. Taking these limitations into account, this article extends the extant literature.

\section{Conclusion}

In this article, we set out to determine the relationships between parent reports of engaging in early learning activities, school entry skills and later performance in Grade 5 mathematics.

In an endeavour to promote school entry skills by engaging parents in the early learning process in South Africa, the issues raised in the article should be taken into account by policymakers. Failure to do so may result in the continuation of children entering Grade 1 without the prerequisite skills base, which may in turn impact later achievement. The role of the home should be emphasised by policymakers, and parents should be encouraged to engage their children in learning activities from an early age, to stimulate their development and prepare them for the formal schooling environment. Children who come from low-income households and children who do not speak the language of instruction at home may require additional support.

\section{Acknowledgements Competing interests}

The authors declare that they have no financial or personal relationships that may have inappropriately influenced them in writing this article.

\section{Authors' contributions}

M.M.V. was the principal author and project manager and was responsible for data construction and analysis. A.L.J. and M.M.V. were involved in the conceptualisation of the study 
and the writing of the article. S.M.H. was involved in the literature review and writing of the article.

\section{Funding information}

The TIMSS 2015 in South Africa was funded by the Department of Basic Education and the Human Sciences Research Council.

\section{References}

Black, M., Walker, S.P., Fernald, L.C.H., Andersen, C.T., DiGirolamo, A.M., Lu, C. et al., 2016, 'Advancing early childhood development: From science to scale 1: Early childhood development coming of age: Science through the life course', Lancet 389, 77. https://doi.org/10.1016/S0140-6736(16)31389-7

Bradley, R.H., 2002, 'Environment and parenting', in M.H. Bornstein (ed.), Handbook of parenting: Volume 2: Biology and ecology of parenting, pp. 281-314, Lawrence Erlbaum, Hillsdale, NJ.

Brinkman, S.A., Hasan, A., Jung, H., Kinnell, A., Nakajima, N. \& Pradhan, M., 2016, The role of preschool quality in promoting child development: Evidence from rural Indonesia, The World Bank. https://doi.org/10.1596/1813-9450-7529

Chin, L.C. \& Zakaria, E., 2015, 'Understanding of number concepts and number operations through games in early mathematics education', Creative Education 6 , 1306-1315. https://doi.org/10.4236/ce.2015.612130

Cunha, F., Heckman, J.J., Lochner, L. \& Masterov, D.V., 2006, 'Interpreting the evidence on life cycle skill formation', in E.A. Hanushek \& F. Welch (eds.), Handbook of the economics of education: Volume 1, pp. 687-812, Elsevier B.V., St. Louis, MO.

Duncan, G.J., Brooks-Gunn, J. \& Klebanov, P.K., 1994, 'Economic deprivation and early childhood development', Child Development 65(2), 296-318. https://doi.org/ $10.2307 / 1131385$

Duncan, G.J., Dowsett, C.J., Claessens, A., Magnuson, K., Huston, A.C., Klebanov, P. et al., 2007, 'School readiness and later achievement', Developmental Psychology 43(6), 1428-1446. https://doi.org/10.1037/0012-1649.43.6.1428

Field, A.P., 2009, Discovering statistics using SPSS, 3rd edn., Sage, London.

Gonyea, R.M., 2005, 'Self-reported data in institutional research: Review and recommendations', New Directions for Institutional Research 127, 73-89. https:// doi.org/10.1002/ir.156

Heckman, J., Stixrud, J. \& Urzua, S., 2006, 'The effects of cognitive and non-cognitive abilities on labour market outcomes and social behaviour', Journal of Labor Economics 24, 411-482. https://doi.org/10.1086/504455

Institute of Medicine, 2000, From neurons to neighborhoods: The science of early childhood development, The National Academies Press, Washington, DC. https:// doi.org/10.17226/9824

Juan, A. \& Visser, M., 2017, 'Home and school environmental determinants of science achievement of South African students', South African Journal of Education 37(1) 1-10. https://doi.org/10.15700/saje.v37n1a1292
Kotze, J., 2015, 'Can pre-grade $\mathrm{R}$ be the stepping stone to social equality in South Africa', South African Journal of Childhood Education 5(2), 1-27. https://doi. org/10.4102/sajce.v5i2.388

Melhuish, E.C., Phan, M.B., Sylva, K., Sammons, P., Siraj-Blatchford, I. \& Taggart, B., $2008 \mathrm{~b}$, 'Effects of the home learning environment and preschool center experience upon literacy and numeracy development in early primary school', Journal of Social Issues 64(1), 95-114. https://doi.org/10.1111/j.1540-4560. 2008.00550.x

Melhuish, E.C., Sylva, K., Sammons, P., Siraj-Blatchford, I., Taggart, B., Phan, M.B. et al., 2008a, 'Preschool influences on mathematics achievement', Science 321 , 1161-1162. https://doi.org/10.1126/science.1158808

Pretorius, E.J., 2014, 'Supporting transition or playing catch-up in Grade 4? Implications for standards in education and training', Perspectives in Education 32(1), 51-76.

Pungello, E.P., Kupersmidt, J.B. \& Burchinal, M.R., 1996, 'Environmental risk factors and children's achievement from middle childhood to early adolescence', Developmental Psychology 32(4), 755-767. https://doi.org/10.1037/0012-1649. 32.4 .755

Ramey, C.T. \& Ramey, S.L., 2004, 'Early learning and school readiness: Can early intervention make a difference?', Merrill-Palmer Quarterly 50, 471-491. https:// doi.org/10.1353/mpq.2004.0034

Reddy, V., Isdale, K., Juan, A., Visser, M., Winnaar, L. \& Arends, F., 2016, TIMSS 2015 Highlights of mathematics achievement of Grade 5 South African learners, Human Sciences Research Council, Pretoria.

Republic of South Africa (RSA), 2015, National integrated early childhood development policy, Government Printers, Pretoria.

Richter, L., Biersteker, L., Burns, J., Desmond, C., Feza, N., Harrison, D. et al., 2012, Diagnostic review of the early childhood development sector, Department of Performance Monitoring and Evaluation in the Presidency, Pretoria.

Schady, N., Galiani, S. \& Souza, A.P., 2006, 'Early childhood development in Latin America and the Caribbean', Economia 6(2), 185-225.

Siegler, R.S., 2009, 'Improving the numerical understanding of children from lowincome families', Child Development Perspectives 3(2), 118-124. https://doi. org/10.1111/j.1750-8606.2009.00090.x

Siegler, R.S. \& Ramani, G., 2009, Playing linear number board games improves children's mathematical knowledge, Society for Research on Educational Effectiveness, Evanston, IL.

Smith, J.R., Brooks-Gunn, J. \& Klebanov, P.K., 1997, 'Consequences of living in poverty for young children's cognitive and verbal ability and early school achievement', in G.J. Duncan \& J. Brooks-Gunn (eds.), Consequences of growing up poor, pp. 132-189, Russell Sage Foundation, New York.

Statistics South Africa, 2017, Poverty trends in South Africa: An examination of absolute poverty between 2006 and 2015, Statistics South Africa, Pretoria.

Taylor, S. \& Coetzee, M., 2013, Estimating the impact of language of instruction in South African primary schools: A fixed effects approach, Stellenbosch Working Paper Series WP 21/2013, viewed 15 October 2018, from https://www.ekon.sun. ac.za/wpapers/2013/wp212013

UNICEF, 2012, School readiness: A conceptual framework, United Nations Children's Fund, New York, viewed 07 November 2017, from https://www.unicef.org/ education/files/Chil2Child_ConceptualFramework_FINAL(1).pdf 